\title{
Sofismo Doutrinário: qual a interpretação Constitucional
} queremos?

\author{
Doctrine's Sophism: What Interpretation Constitutional We \\ Want?
}

\author{
Flavio Quinaud Pedron ${ }^{1}$ \\ Rosa Lima Castro ${ }^{2}$
}

\begin{abstract}
RESUMO
O título do trabalho já é em si uma ironia, o desejo não pode ser a porta de entrada para o processo interpretativo. A doutrina oferece um leque de opções metodológicas, o jurista se serve, como em um banquete à la carte, fartando-se de discricionariedade arrota impropérios jurídicos. Quais as origens dos princípios interpretativos amplamente divulgados como supremas verdades no Brasil? Existe coalização entre os métodos apresentados em "manuais" de Direito Constitucional? Como (e, será que) os Tribunais Superiores utilizam a doutrina como fonte de Direito? Há um aspecto nefasto nesta perpetuação do saber irrefletido ou será apenas descuido teórico? São estes questionamentos que (não) pretendemos responder ao longo deste artigo, mas antes despertar o senso crítico no leitor, que a partir de agora, deve questionar a veracidade de tudo que lhe é posto. É da inquietude que nasce o conhecimento.
\end{abstract}

\section{PALAVRAS-CHAVE:}

Direito e Literatura. Linguística. Hermenêutica filosófica. Teoria da Decisão.

\begin{abstract}
The title of the work is already in itself an irony; the desire cannot be the gateway to the interpretative process. The doctrine offers a range of methodological options, the jurist serves, as in an a la carte banquet, brimming with discretion bursts legal improprieties. What are the origins of the interpretive principles widely divulged as supreme truths in Brazil? Is there a coalition between the methods presented in "manuals" of Constitutional Law? How (and, is it) that the High Courts use doctrine as a source of law? Is there a nefarious aspect in this

\footnotetext{
${ }^{1}$ Possui mestrado (2006) e doutorado em Direito (2011) pela Universidade Federal de Minas Gerais (UFMG). Atualmente é Professor Adjunto do Mestrado em Direito da UniFG (Bahia). Professor Adjunto IV da Pontifícia Universidade Católica de Minas Gerais (graduação e pós-graduação). Professor Titular III na graduação do IBMEC. Membro do Instituto Brasileiro de Direito Processual (IBDP). Membro da Associação Brasileira de Direito Processual Constitucional (ABDPC). Membro da Associação Brasileira de Direito Processual (ABDPro). Membro da Associação Norte-Nordeste de Professores de Processo (ANNEP). Membro da Rede Brasileira de Direito e Literatura (RDL). Membro da Comissão de Direito Processual da OAB/MG. Membro do Conselho Editorial da Revista do Centro de Estudos da Justiça Federal (CEJ/ STJ - Conselho da Justiça Federal), da Revista Jurídica da Presidência da República, da Revista do Instituto de Hermenêutica Jurídica (IHJ), da Revista "Direito, Estado e Sociedade" (PUC-Rio), entre outras revistas científicas jurídicas. Advogado.

2 Mestre em fundamentos e efetividade do Direito pelo programa de pós-graduação stricto sensu do Centro Universitário de Guanambi (UniFG). Pós-graduada em Direito e magistratura pela Universidade Federal da Bahia (UFBA) em parceria com a Escola de Magistratura da Bahia (EMAB). Bacharel em Direito pela Faculdade Independente do Nordeste (FAINOR). Pesquisadora no Grupo Ser Tão - Núcleo Baiano de Direito e Literatura. Advogada com inscrição na OAB/BA.
} 
perpetuation of unreasonable knowledge, or is it merely theoretical neglect? It is these questions that we (not) intend to answer throughout this article, but rather awaken the critical sense in the reader, who from now on must question the truthfulness of everything that is put to him. It is from restlessness that knowledge is born.

\section{KEYWORDS:}

Law and Literature. Linguistics. Philosophical Hermeneutics. Decision Theory.

\section{INTRODUÇÃO}

Pensemos no contexto histórico-cultural de formação do Brasil, filhos de uma nação colonizada, ainda trabalhamos arduamente para construção de uma identidade própria. No ambiente acadêmico, este desafio também se faz presente, não sendo menos árdua a mesma tarefa em construção.

Llosa (2012), em seu Civilização do Espetáculo denuncia a sociedade de frivolidades que se instaurou ao decorrer do tempo, atingindo seu ápice na Era Contemporânea. É ilusório pensar que a presença da educação e da cultura automaticamente emancipa o homem, ou melhor, o humaniza. Por vezes a universidade perpetua os preconceitos arraigados nas camadas sociais mais profundas.

Esta cultura pós-moderna vivenciada por nós, produz conhecimento hermético, isolado em si mesmo. O fenômeno pode ser observador em dois aspectos. Primeiro, não há interdisciplinaridade $^{3}$, as matérias são lecionadas de maneira estanque, as universidades formam mais tecnólogos do que pensadores do Direito. Em segundo lugar, a cultura, o ensino jurídico e as artes, não conseguem resolver as mazelas sociais, quando muito, amenizam os sofrimentos ou criam a ilusão, a distração, a alienação das massas (BAUDRILLARD, 2004).

\footnotetext{
${ }^{3}$ Vide a grande novidade que é considerada os estudos de Direito e Literatura no Brasil, algo tão elementar, e inerente aos estudos jurídicos.
} 
A crítica aos moldes tradicionais do ensino jurídico é feita por muito teóricos como Warat (2002) e Streck (1999), que também tecem comentários acerca dos equívocos interpretativos (ensinados na faculdade, e, reproduzidos nos tribunais) que servem como mecanismos de perpetuação do poder.

Grosfoguel (2016), Castro-Gómez (2007), Chauí (2013) e Santos (2011), atribuem este déficit no ensino superior e a reprodução impensada de conteúdos à importação do modelo europeu tradicional, que não se adequaria às necessidades peculiares da América Latina. Para estes autores, a importação de conceitos perpassa por um processo ideológico de dominação e autoritarismo.

Por fim, Silva (2005), faz um resgate histórico, vai as origens, busca entender de onde surge a teoria interpretativa que vigora no campo constitucional, e, verifica se ela faz sentido no nosso contexto sócio-político.

Assim, através da pesquisa bibliográfica, tendo os autores citados acima como referência básica, este trabalho faz uma radiografia do ensino jurídico no Brasil, por entender que é através dele e da doutrina que conceitos são solidificados e difundidos.

Buscaremos compreender, especificamente, quais métodos interpretativos estão sendo difundidos na academia e utilizados nos Tribunais, para justificar os posicionamentos jurisdicionais em matéria constitucional.

\section{SOBRE COMO ESTAMOS CONSTRUINDO CONHECIMENTO JURÍDICO NO UNIVERSO ACADÊMICO DO BRASIL - BREVE HISTÓRICO}

Castro-Gómez (2007, p.82) afirma que, a partir de 1492, a forma de construção do saber é drasticamente modificada, se opera neste momento a cisão entre o homem e a natureza, a visão orgânica do mundo é superada. A razão toma frente na busca por conhecimento, o objetivo passa a ser "categorizar" cada coisa, decompondo a realidade em fragmentos para assim, dominá-la. 
Então, conforme o autor citado acima (CASTRO-GÓMEZ, 2007, p.82), surge com o cartesianismo um método estritamente racional, matemático e neutro para percepção do objeto estudado. Toda sensação humana deveria ser expurgada nesta busca epistemológica. Não há neste ponto, nenhuma preocupação moral, a ciência é meramente descritiva.

Institui-se o que Castro-Gomez (2007, p.81) denomina hybris del punto cero, algo, traduzido livremente como hybris do ponto zero. Hybris é um termo grego que significa indolência, soberba, orgulho imprudente, excesso, violência irrefletida. O autor considera que o cientista moderno pretende observar o mundo como um Deus, que do alto do pedestal, observa a tudo, imparcialmente, estando apto a expor seu ponto de vista, não se submetendo, entretanto, ao ponto de vista alheio.

Isto importa, porque, para o autor, nas universidades o conhecimento tem sido produzido desta maneira, a partir da hybris del punto cero. Os campos do saber são fragmentados e seguem apenas uma linha teórica tradicional. Os cânones são instrumentos de poder, materializados para solidificar o conhecimento, no sentido mais puro de enrijecimento e perpetuação do saber.

Para Castro-Gómez, as universidades reproduzem o ambiente pós-colonial e capitalista em que estão inseridas. O conhecimento é produzido de forma compartimentalizada, cada disciplina é ensinada de forma estanque, os mesmos autores clássicos são trabalhados da mesma maneira há séculos.

Óbvio que o discurso aqui não se impõe contra autores tradicionais, que aliás, sempre serão revisitados. Como bem lembra Calvino (2007), um clássico é aquele que nunca terminou de dizer o que se propôs, uma nova leitura sempre enriquecerá o pesquisador. A crítica em verdade, se instala na adoção (exclusiva) de obras advindas do eixo europeu.

O modelo de mercado globalizado contribui para perpetuação desta crise institucional nas universidades. A produção do saber obedece à lógica traçada por multinacionais, que por vezes financiam as pesquisas, deixando de lado os interesses do Estado no processo educacional. Impossível neste contexto separar conteúdo científico de mero discurso ideológico. O conhecimento serve "apenas" para perpetuação do poder. 
Santos (2011) denuncia este triste quadro, quando observa que na universidade somos incentivados a produzir conhecimento, aumentar a produtividade como se fosse algo abstrato e individual, mas que em verdade, estamos trabalhando para oferecer às grandes empresas o aumento de sua mais-valia.

Sobre a importação irrefletida de conceitos, Chauí (2013, p.15), afirma que:

Tem sido frequente a afirmação de que uma das fontes da fraqueza teórica do pensamento brasileiro e, em particular, da ideologia no Brasil decorre da tendência a importar ideias. Estas, que possuem sua razão de ser ali onde são originariamente produzidas, quando transplantadas para o Brasil convertem-se em superfetação e ornamento grotesco.

Seguindo este paradigma, ao estudar a interpretação constitucional, buscamos no ambiente acadêmico do Brasil (diga-se de passagem, quando o trabalho é feito de maneira menos superficial) a obra de Konrad Hesse (1998), Elementos de Direito Constitucional da República da Alemanha, ainda que a referência a tal texto muitas vezes fique oculta ou passe desconhecida pelo manual que a reproduz. Esta obra foi traduzida para o português e foi popularizada, principalmente, por Canotilho, sendo adotada como fonte quase exclusiva de pesquisa, por inúmeros manuais de Direito Constitucional quando abordam os temas da metodologia e da interpretação constitucional. Virgílio Afonso da Silva (2005), faz este trabalho de resgate de memória, clarificando a origem da teoria.

\section{O ESTUDO DA INTERPRETAÇÃO CONSTITUCIONAL NO BRASIL - ENTRE HESSE E CANOTILHO}

Importante iniciar nossos estudos admitindo que existem dois grupos metodológicos diferentes, o primeiro deles, o método clássico, desenhado por Savigny (2001), e composto pelos seguintes caminhos: gramatical, sistemático, lógico e histórico. A sua proposta de dogmática para o direito, então, serve ao trabalho de "atualização" do direito romano, mas também de criação e de manutenção de uma tradição imaginada artificialmente. Assim, por 
meio de uma proposta de construção de uma história do direito, com Savigny (2001), surge a uma tensão: de um lado, o dogma, de outro, a história.

Ainda dentro dessa metodologia clássica, podemos destacar os trabalhos e pesquisa de Betti (1995), como uma versão mais sofisticada daquilo que foi iniciado por Savigny. A partir do pensamento positivista, a história era reduzida ao primado dos fatos sociais (como figuras autônomas e fundantes) e o direito era compreendido, por sua vez, como mera forma. Betti (1995, p.339) parece realmente acredita que a sua hermenêutica seja capaz de fornecer uma resposta objetiva para as ciências do espírito e, assim, o intérprete, em um "diálogo amigável com o passado", é capaz de realizar um encontro perfeito, por meio da interpretação, com o que o texto "realmente" significa (COSTA, 2010, p.32). Como reflexo disso, a dogmática hodierna passa a funcionar como um "instrumento de intelecção do direito passado"; ou, dito de outra forma, “a dogmática jurídica é o 'nome' melhor para 'coisa' jurídica do passado" (COSTA, 2010, p.33). A dogmática, portanto, torna possível o diálogo entre o momento atual (presente) e o passado; e, ainda, faz contínua a ideia de tradição. Ora, assim, o que parece ser a inovação de Betti (1995) é apenas um retorno a Savigny (2001), como observa Costa (2010, p.33). O mais importante é que tal quadro vai ter uma função pragmática essencial: o de permitir à história do direito assumir uma dignidade própria e deixar de ser "o patinho feio da faculdade de direito", habilitando-se para dialogar em condições de igualdade com as demais disciplinas jurídicas (COSTA, 2010, p.33-34).

O segundo grande grupo é considerado "inovador e moderno", sendo exclusivamente voltado ao campo constitucional e, via de regra, na doutrina pátria se apresenta como "princípios"4 interpretativos: da unidade da constituição, do efeito integrador, da máxima efetividade, da conformidade funcional, da concordância prática, da força normativa da constituição, da interpretação conforme a constituição, da máxima efetividade e o da interpretação conforme a constituição.

O rol mencionado acima foi apresentado por Virgílio Afonso da Silva (2005, p. 120), em seu artigo Interpretação Constitucional e Sincretismo Metodológico, no qual denuncia a

\footnotetext{
${ }^{4}$ Há aqui uma clara deficiência epistemológico-jurídica naqueles que assumes os instrumentos teóricos definindoos (ou até confundindo-os) com princípios jurídicos. Acabam denotando que não compreenderam as teorias contemporâneas acerca do tema, e só fazem uso da terminologia "princípio" por mera retórica, como uma figura de linguagem para destacar sua intrínseca importância (PEDRON, 2012).
} 
adoção cega no Brasil de métodos e de teorias importados do Direito Alemão, que em sua essência mantêm os mesmos vícios dos métodos clássicos rechaçados pela mesma doutrina. Silva (2005, p.117) identifica que os métodos advêm da obra de Konrad Hesse, mas que são cunhados originalmente por Böckenförde (1993).

Silva (2005), crítica ainda a adoção unanime deste rol pelos manuais de Direito Constitucional brasileiros. Acontece que o posicionamento adotado por alguns doutrinadores carece de fundamentação teórica e de referência bibliográfica correta; desse modo, tais obras brasileiras parecem fazer uma confusão e uma caricatura extremamente reduzida das teorias alemãs.

Vejamos, observando alguns livros de Direito Constitucional, que são normalmente utilizados em cursos de graduação por todo o país, percebe-se a repetição deste rol sem, contudo, mencionar se quer o seu "pai" idealizador de tal pensamento, quer seja Hesse ou mesmo Böckenförde. Autor frequentemente mencionado nesses trechos é Canotilho (discípulo de Hesse), que conforme Silva (2005, p.134), foi o responsável pela divulgação da teoria em língua portuguesa.

Selecionamos três obras, tendo como critério a sua popularidade entre os estudantes de Direito, bem como, sua presença massiva em ementas de Direito Constitucional em cursos de graduação ou em editais de concursos públicos:

1) Direito constitucional esquematizado, de Pedro Lenza (2017);

2) Direito constitucional descomplicado, de Marcelo Alexandrino e Vicente Paulo (2016);

3) Curso de Direito Constitucional, de Manoel Gonçalves Ferreira Filho (2012).

Lembramos que a análise crítica das obras aqui selecionadas não tem o intuito pejorativo, é feita com todo respeito possível, sem retirar o mérito dos autores que possuem, notoriamente, vasto conhecimento jurídico.

Na primeira obra escolhida, Lenza (2017, p. 160), enumera os métodos e os "princípios" interpretativos. Na primeira secção, não há nenhuma referência ao Böckenförde, sendo mencionado, entretanto apenas Canotilho. Os métodos listados são: hermenêutico clássico, tópico-problemático, hermenêutico-concretizador, científico-espiritual, normativo-estruturante e o da comparação constitucional. 
No quesito "princípios" são apresentados por Lenza (2017, p.163): o da unidade da Constituição, efeito integrador, máxima efetividade, justeza, harmonização, força normativa, interpretação conforme a constituição e proporcionalidade. Aqui também há menção ao Canotilho, e especificamente no Princípio da Força Normativa, aparece trecho da obra de Gilmar Mendes citando Hesse (LENZA, 2017, p.165).

Na segunda obra escolhida, Alexandrino e Paulo (2016, p.69), mencionam os mesmos métodos citados por Lenza (2017). Os “princípios” encontrados também foram os mesmos, com exceção o da proporcionalidade, não incluído nesta obra. Mais uma vez, fazem menção a Canotilho, mas nem uma palavra se quer sobre Böckenförde, e Hesse só está presente quando da explicação sobre o Princípio da Força Normativa da Constituição.

Vamos à análise da terceira e última obra. Ferreira Filho (2012, p.277), faz uma abordagem um pouco diferente. Para ele interpretação legítima é apenas aquela que busca o sentido da norma, a vontade do legislador, qualquer ato interpretativo que fuja deste caminho é considerado pelo autor como "sofismo". Nos métodos, este autor relaciona apenas aqueles clássicos catalogados por Savigny. E quanto aos "princípios", apresenta o mesmo rol utilizado por Lenza (2017), atribuindo sua autoria exclusivamente a Canotilho, ou seja, também se omite a importância de Hesse.

Da análise das três obras doutrinárias, que se apresentam como clássicos a esta geração de novos juristas e de juristas em formação, sendo frequentemente adotada por alunos de graduação e um novo grupo que se dedica apenas aos concursos, fica a lição da importância do aprofundamento nos estudos.

Com o minucioso trabalho investigativo realizado por Silva (2005), pode-se compreender que o caminho epistemológico adotado por estes "manuais" não é o mais seguro e mais fidedigno. Fica em aberto o questionamento, se tal ato é perpetrado por descuido ou posição ideológica.

Veremos no tópico posterior, como os métodos e os "princípios" podem ser utilizados para perpetuação do poder. Com isto, podemos refletir se os manuais "persistem no erro" com o objetivo de mascarar o caminho "verdadeiro", que levaria a interpretação plena e íntegra. 
Indo direto a fonte, Hesse (1998, p.53), em sua obra Elementos de Direito Constitucional da República Federal da Alemanha, reserva um capítulo inteiro para tratar da interpretação. O título do livro já nos remete à ideia de que não era a intenção do autor criar uma teoria universal, e, mediante a leitura, começam a surgir as incompatibilidades com o sistema jurídico brasileiro.

Em primeiro lugar, a diferença reside na estrutura interna dos sistemas jurisdicionais. Hesse (1998, p.54) menciona o Tribunal Constitucional Federal, órgão que existe na Alemanha responsável por fiscalizar a obediência à Lei Fundamental do país. Diferente do Supremo Tribunal Federal do Brasil, aquele, não recebe recursos processuais, não tem função política, nem aplica diretamente a lei.

Hesse (1998, p.58) demonstra preocupação com o aspecto prático dos métodos interpretativos, já que sua aplicação isolada diverge totalmente das normas impostas por eles mesmos. Ele crítica as interpretações sistêmica e teleológica, considerando esta última uma "carta em branco" para exprimir a vontade do órgão julgador. Posteriormente ele (HESSE, 1998, p.64) demonstra que os métodos tradicionais podem ser úteis, se aplicados de maneira correta.

Vamos ao ponto fulcral, o método (realmente) proposto por Hesse (1988, p.61), para interpretação da Lei Fundamental Alemã. Citando Gadamer e Böckenförde, ele começa a construir sua visão de interpretação constitucional como concretização. Realmente lista os "princípios" interpretativos da unidade da Constituição, da concordância prática, da exatidão funcional, do efeito integrador e da força normativa da Constituição. A diferença aqui, é que são citados em um contexto que faz todo sentido.

O "princípio" que menos se adequa à realidade do Brasil, como bem observado por Silva (2005, p.128) é o da exatidão funcional (HESSE, 1998, p.67), que "abrasileirado" tornou-se o princípio interpretativo da justeza (LENZA, 2017, p.164). Aqui, o sentido adotado foi de preservação da separação de poderes. O autor original, Hesse, elabora este princípio para evitar a ingerência do Tribunal Constitucional alemão na atividade do legislador e, com isso, uma interferência ilegítima. Vejamos: 
em uma determinada forma, então o órgão interpretador tem de manter-se no quadro das funções a ele atribuídas. (...) Em especial, isso vale para a relação entre legislador e Tribunal Constitucional. (HESSE, 1998, p.67)

Ocorre que no Brasil, o STF possui função político-jurídica (PAIXÃO, 2007); assim, pode se imiscuir na fiscalização do Legislativo nas hipóteses que a Lei autoriza. Concordamos que o STF não pode ultrapassar os limites estabelecidos na legislação e nem na Constituição, porém, este não é o sentido do "princípio" da exatidão preconizado por Hesse (1998).

Para finalizar esta etapa do trabalho consideremos que, Silva (2005) explica que os métodos e "princípios" interpretativos difundidos amplamente pela doutrina colidem entre si, não possuem aplicabilidade prática e não coadunam com o nosso sistema judiciário. Em sua essência os princípios elencados pelos doutrinadores em nada diferem dos cânones tradicionais elencados por Savigny.

Se forem colocados a prova, através de um raciocínio lógico-argumentativo, fica claro que o texto constitucional deve ser analisado como um todo (unidade da Constituição), aplicado levando em conta todos os seus aspectos e de maneira mais efetiva possível (efeito integrador e máxima efetividade), sem violar a separação de poderes (justeza), e que é dotado de valor legal (força normativa da constituição).

Os "princípios" trazem obviedades, que se aproximam do que dizia os métodos clássicos, por exemplo, o teleológico, que buscava encontrar o sentido final da norma (máxima efetividade) ou como o histórico, que trás uma visão holística do texto (unidade da constituição).

No próximo tópico apresentaremos críticas a este modelo, e possíveis soluções apresentadas por doutrinadores de renome que constroem uma teoria argumentativa dotada de aplicabilidade prática e responsabilidade moral. 


\section{ALGUNS PASSOS PARA CONSTRUÇÃO CORRETA DE UMA CULTURA INTERPRETATIVA DO DIREITO}

Segundo Santos (2011, p.41) o totalitarismo não se resume a difusão de informações falsas, nem apenas de estabelecimento de padrões no mundo da política, e do trabalho, através da globalização. Ele "invade o mundo da pesquisa e do ensino universitário, mediante um cerco às ideias cada vez menos dissimulado".

Chauí (2013, p.16), denuncia a prática de importação de ideias como forma de perpetuação do pensamento autoritário no Brasil:

\footnotetext{
Se admitirmos ser constitutiva da lógica do pensamento autoritário a necessidade de encontrar um saber prévio sobre o qual possa apoiar-se, bem como a necessidade de manipular fatos nos quais possa exemplificar-se e, graças a tais procedimentos, evitar o risco da elaboração do conhecimento, torna-se clara a debilidade teórica e a exigência de importar ideias já consagradas alhures.
}

Por esta razão nos questionamos se a reprodução de padrões interpretativos vazios de sentido é déficit epistemológico (desleixo ou talvez ignorância) ou corrupção ideológica (ato maquiavélico). Streck (2017, p. 143) afirma que:

Os métodos de interpretação recebem diversas e severas críticas da doutrina por sua potencial ocultação da subjetividade do intérprete, na medida em que cada método pode conduzir a um resultado interpretativo diverso e a escolha é realizada livremente pelo sujeito.

Warat (1994, p.65) reserva um capítulo inteiro de sua obra Introdução ao Estudo do Direito, para demonstrar que os métodos interpretativos podem servir como recurso ideológico e político. Ele inicia seu texto elencando os métodos e suas escolas correspondentes, utilizando para isto o critério temporal.

Menciona o método gramatical, o exegético, o histórico, o comparativo, o científico, o sociológico, o tópico-retórico e o teleológico. Além disto, faz referências as escolas: do direito livre, do positivismo fático, e a egológica. 
Passamos a expor os métodos de mais relevância na doutrina brasileira, utilizando como critério de escolha sua ocorrência nos livros de Direito Constitucional analisados no tópico anterior.

Primeiro, aparece o método gramatical (WARAT, 1994, p.66), criado à época do Código Civil Napoleônico pela Escola da Exegesa, que atribui sentido literal às palavras contidas na lei. Depois, o método exegético (WARAT, 1994, p.68), que também surge neste cenário, apresentando uma pequena mudança, busca encontrar a vontade do legislador. Ora, não há melhor maneira para impor os ideais burgueses do que os relacionas a essa figura mítica do “espírito do legislador". O método exegético permite a construção de argumentos quase inquestionáveis, ao fundar suas bases em algo metafísico. Pressupõe a existência de um juiz neutro, bem como reduz a noção de interpretação como ato de conhecimento e não de vontade, privilegia o formalismo e a segurança jurídica (entendida meramente como previsibilidade de decisão) em detrimento de uma concepção determinada de justiça.

O terceiro método alvo de críticas para Warat (1994, p.70) é o histórico, que cria uma fantasia de unidade coletiva como fonte de Direito. Da mesma forma que ocorre com o método exegético, é difícil combater argumentos vazios, com o agravante, aqui, de não contar com a legislação escrita, esquematizada, e sim com os costumes, que podem ser interpretados livremente. Aqui o apelo é direcionado à "consciência crítica universal".

Seguindo o recorte teórico proposto acima, partimos para análise crítica proposta por Warat (1994, p.81) ao método teleológico, presente em todos os manuais de Direito Constitucional analisados no tópico anterior. Este é dividido em teleológico em sentido estrito (que se contrapõe à Teoria de Kelsen), e em sentido amplo (que é em suma a jurisprudência de interesses), ambos são antinormativistas e tem como precursor Ihenring. Aqui o importante é que a norma alcance a sua finalidade, a ideia de fim sobrepõe à de valor.

O problema é que deste modo, critérios sociais, morais e políticos deverão ser utilizados como parâmetros decisionais, e essa escolha preocupa. Em nome do interesse social, decisões arbitrárias podem ser tomadas, sem qualquer critério lógico valorativo, baseando-se unicamente em interesses políticos. 
Concluindo a análise dos métodos, Warat (1994, p.88) se utiliza do termo “álibi teórico", para se referir àqueles que em um ato político, fundamentam suas decisões jurídicas. Se valendo do método para justificar seus preconceitos, para perpetuar o modelo de opressão vigente, para dotar de cientificidade aquilo que é doxa.

Os métodos interpretativos, como são utilizados, servem para perpetuar a ilusão de rigor científico, de neutralidade das decisões judiciais, quando, em verdade, contribuem para perpetuação das crenças jurídicas arraigadas em nossa sociedade, perpetuam uma história de dominação política e social.

Entretanto, se a interpretação é necessária e inerente ao Direito, como proceder de forma correta - no sentido de uma moralidade jurídica -, em busca da integridade das decisões, e da própria ciência jurídica?

Vejamos, Silva (2008) e Dworkin $(2014,1999)$ apresentam algumas propostas.

Dworkin (2014, p.243) considera que só pode haver entendimento entre as partes, se estas estiverem partindo da mesma definição conceitual dos temas debatidos. Assim, importante destacar que para este autor, o conceito doutrinário de Direito só pode ser um conceito interpretativo $^{5}$ (2014, p.619).

Partindo deste pressuposto, vamos ao posicionamento do autor sobre interpretação jurídica.

Dworkin (1999) também considera que deve haver consenso na escolha da prática interpretativa. Este "acordo pré-interpretativo, contingente e local" (DWORKIN,19,99, p.113) possibilita o diálogo e o entendimento entre os juristas. Mas é em Uma questão de Princípio que o autor (DWORKIN, 2001, p.175) vai apresentar a possibilidade de encontrar uma resposta correta por meio do processo interpretativo.

Mas devemos compreender bem em que se constitui a tese da Resposta correta Dworkiniana (PEDRON, 2005, p.73). Segundo Dworkin (2002; PEDRON, 2001, p.235-236) para vencer a discricionariedade em casos difíceis, ante a ausência de uma regra previamente

\footnotetext{
${ }^{5}$ Tese defendida em várias obras do mesmo autor, como em Dworkin (1999, p.109 ou 2001, p. 175).
} 
definida, deve se lançar mão de dois artifícios demonstrados por metáforas: o Juiz Hércules e o Romance em Cadeia. Para ele os direitos são frutos da história e da moralidade (DWORKIN, 2002).

Vejamos, Juiz Hércules de Dworkin (PEDRON, 2005, p.74) seria uma metáfora que representa um magistrado irreal extremamente paciente e habilidoso, que seleciona criteriosamente a prática interpretativa a ser adotada, através do filtro da integridade, fazendo da interpretação construtiva no Direito (PEDRON, 2012). Com Hércules, Dworkin não está recorrendo a nenhuma figura metafísica, a exemplo de uma posição original ou um véu da ignorância, como fez Rawls (1971; BONFIM e PEDRON, 2017). Ao contrário, Dworkin assume apenas um exemplo do que seria uma postura hermenêutica consciente e responsável por seus atos, que busca colocar tudo à sua melhor luz. Dessa forma, todos nós podemos ser Hércules, se aceitarmos modificar nossa postura diante do nosso quotidiano jurídico.

Já o Romance em Cadeia, outra metáfora dworkiniana, significa que o magistrado deve guardar a coerência histórica entre a decisão que toma no presente, e as que foram proferidas no passado (DWORKIN, 2001; PEDRON, 2005, p.74). Não cabe ao magistrado apenas reproduzir mecanicamente aquilo que foi decidido por outros tribunais, mas buscar sempre desenvolver o direito da forma a garantir a cada nova decisão iguais direitos e consideração aos partícipes do iter processual. Ele tem um dever moral de dialogar com a história institucional de maneira crítica, inclusive sendo capaz de identificar no interior desse discurso erros de interpretação e de decisão institucionalizados, e, em sua decisão, demonstrar esses equívocos na busca da decisão correta (DWORKIN, 2001).

Assim, Dworkin não só afirma que é possível encontrarmos uma resposta correta ao caso concreto, como é extremamente recomendável que a busquemos. A busca, não assegura a certeza, mas garante o pressuposto lógico e a argumentação moral que servirá de baliza à fundamentação da decisão.

Streck (2017, p.141), explica o caminho que os métodos interpretativos aplicados ao Direito tomam, desde os primórdios, com a tentativa de unificação com aqueles das ciências naturais, passando pela hermenêutica, e por fim, chegando até a fenomenologia, e a própria hermenêutica filosófica. O autor, ancorado na teoria de Gadamer (2005), ressalta que "o acontecer da verdade não está condicionado a um método pré-estabelecido de conhecimento.”. 
Silva (2008, p. 318), lembra que a interpretação jurídica não se restringe às normas, antes, toca também na questão fática, em sua contextualização histórica e, portanto na aplicação concreta para criação jurisprudencial do Direito. Ela (2008, p.332) afirma que: "A diversidade, plasticidade e complexidade da vida real só cabem no Direito através da interpretação.”.

Para Silva (2008), a questão fulcral da interpretação reside no modo que o jurista vai lidar com os fatos, quais serão considerados juridicamente relevantes, como se dará a "livre" apreciação das provas, quando muitas vezes os dados trazidos ao processo se apresentam de forma contraditória.

O mais natural é que um processo se forme assim, pensando em uma hipótese em matéria criminal, o advogado apresenta uma versão dos fatos através de queixa crime, o promotor pode denunciar ou não, o que é contestado em sede de resposta à acusação. Segue o curso da ação penal, um emaranhado de versões do mesmo fato, organizados em uma sequência lógica, para que no fim, seja proferida a sentença.

Citando Bruner (2014, p.53): "histórias jurídicas são narrativas na estrutura, adversativas no espírito, inerentemente retóricas na intenção, e justificadamente abertas à suspeita"

Por vezes, nos Tribunais, encontramos uma racionalidade formal, onde há menção aos métodos/princípios interpretativos por questões de praxe. A solução proposta pela autora (SILVA, 2008, p.336) é limitar a discricionariedade judicial através de uma racionalidade prática e concreta, que sirva de baliza decisional.

Com estes dois exemplos teóricos, trazidos por Silva (2008) e Dworkin $(1999,2004)$, fica demonstrado que é possível se praticar no Brasil, uma teoria da argumentação forte, com aplicação efetiva de "princípios" interpretativos que norteiem as decisões judiciais. 


\section{CONCLUSÃO}

O que se difunde são ideologias, não informações. É preciso que haja a reelaboração do discurso no meio acadêmico e na doutrina jurídica pátria.

Em verdade, os métodos interpretativos do texto constitucional são erroneamente utilizados (quando o são), e por vezes aplicados tardiamente apenas para justificar o posicionamento já adotado. Servem como forma de disfarce teórico, para defesa de determinada posição política ou ideológica.

A repetição de teorias importadas de países estranhos, além de não satisfazer nossas necessidades locais, é feita com total esvaziamento de sentido. Os princípios mencionados exaustivamente acima, são semelhantes entre si, trazem conceitos ultrapassados, e sem nenhuma aplicabilidade prática.

Como desejamos formar profissionais de excelência, com capacidade crítica, se na academia não fornecemos as ferramentas para o desenvolvimento destas habilidades? Como pode o aluno, futuro advogado, magistrado, professor, encontrar-se apto para interpretar a Constituição Federal se tudo que aprendeu foram conceitos vazios?

Existe uma cultura jurídica que vigora no país, sobretudo por juristas mais antigos, de que magistrado não aplica diretamente o texto constitucional. Surge uma nova geração, que entrou na academia já sob a égide da Constituição Federal de 1988, que se incomoda, simplesmente não aceita estes velhos paradigmas postos.

O percurso interpretativo adotado na decisão deve estar claro, para que qualquer leitor esteja apto a compreender como o jurista chegou àquela conclusão. Mesmo que não haja consenso, deve prevalecer o entendimento, a argumentação lógica.

Chega de fecharmos os olhos, de repetirmos teorias apenas porque elas devem constar em aulas ou livros. Vamos construir a partir de hoje, um legado sólido para os futuros acadêmicos construírem seu próprio saber. 


\section{REFERÊNCIAS}

ABBOUD, Georges; CARNIO, Henrique Garbellini; OLIVEIRA, Rafael Tomaz de. Introdução à teoria e à filosofia do direito. $3^{\mathrm{a}}$ ed. São Paulo: Editora Revista dos Tribunais, 2015.

BRUNER, Jerome. Fabricando histórias: direito, literatura, vida. São Paulo: Letra e Voz, 2014.

ALEXANDRINO, Marcelo; PAULO, Vicente. Direito constitucional descomplicado. $15^{\mathrm{a}} \mathrm{ed}$. Rio de Janeiro: Forense; São Paulo: Método, 2016.

BAUDRILLARD, Jean. A sombra das maiorias silenciosas: o fim do social e o surgimento das massas. Trad. Suely Bastos. São Paulo: Brasiliense, 2004.

BÖCKENFÖRDE, Ernst-Wolfgang. Escritos sobre Derechos Fundamentales. Baden-Baden: Nomos, 1993.

BETTI, Emilio. Teoria Generale della interpretazione. Milano: Giuffrè, 1995.

BONFIM, Vinícius Silva; PEDRON, Flávio Quinaud. A razão pública conforme John Rawls e a construção legítima do provimento jurisdicional no STF. Revista de Informação Legislativa, v. 54, n. 214, p. 203-223, abr./jun. 2017. Disponível em: <http://www12.senado.leg.br/ril/edicoes/54/214/ril_v54_n214_p203>.

BRUNER, Jerome. Fabricando histórias: direito, literatura, vida. São Paulo: Letra e Voz, 2014.

CALVINO, Ítalo. Por que ler os clássicos. Tradução de Nilson Moulin. São Paulo: Companhia das Letras, 2007.

CASTRO-GÓMEZ, Santiago. Decolonizar la universidad. La hybris del punto cero y el diálogo de saberes. El giro decolonial. Reflexiones para una diversidad epistémica más allá del capitalismo global, p. 79-91, 2007. Disponível em: http://people.unica.it/riccardobadini/files/2012/04/el-giro-decolonial.pdf\#page=79. Acesso em 22 de junho de 2018.

CHAUÍ, Marilena. Convite à filosofia. 15ª Edição. Editora Ática: São Paulo, 2005.

Manifestações ideológicas do autoritarismo brasileiro. v.2. Org. André Rocha. São Paulo: Editora Fundação Perseu Abramo, 2013.

COSTA, Pietro. Soberania, Representação, Democracia: ensaios de História do Pensamento Jurídico. Curitiba: Juruá, 2010. [Biblioteca de História do Direito].

DWORKIN, Ronald. O império do direito. Tradução Jefferson Luiz Camargo. São Paulo: Martins Fontes, 1999. 
. Uma questão de princípio. São Paulo: Martins Fontes, 2001.

. A raposa e o porco-espinho: justiça e valor. Tradução de Marcelo Brandão Cipolla. São Paulo: WMF Martins Fontes, 2014.

. Levando os Direitos a Sério. Tradução de Nelson Boeira. São Paulo: Martins Fontes, 2002. [Direito e Justiça].

FERREIRA FILHO, Manoel Gonçalves. Curso de Direito Constitucional. 38 a ed. São Paulo: Saraiva, 2012.

GADAMER, Hans-Georg. Verdade e Método: Fundamentos de uma hermenêutica filosófica. 7 ed. Tradução de Enio Paulo Giachini. Petrópolis, Vozes, 2005.

GROSFOGUEL, Ramón. A estrutura do conhecimento nas universidades ocidentalizadas: racismo/sexismo epistêmico e os quatro genocídios/epistemicídios do longo século XVI. Revista Sociedade e Estado, v. 31, n. 1, p. 25-49, Janeiro/Abril 2016. Traduzido por Fernanda Miguens, Maurício Barros de Castro e Rafael Maieiro. Revisão: Joaze Bernardino Costa. Disponível em http://www.scielo.br/scielo.php?pid=S0102-69922016000100025\&script=sci_arttext. Acesso em 10 de junho de 2018.

HESSEE, Konrad. Elementos de direito constitucional da República Federal da Alemanha. Tradução de Luís Afonso Heck. Porto Alegre: SA Fabris Editor, 1998.

LENZA, Pedro. Direito Constitucional esquematizado. 21ª ed. São Paulo: Saraiva, 2017.

LLOSA, Mario Vargas. A civilização do espetáculo: uma radiografia do nosso tempo e da nossa cultura. Trad. Ivone Benedeti. Rio de Janeiro: Objetiva, 2012.

PAIXÃO, Leonardo André. A função política do Supremo Tribunal Federal. 2007. Tese de Doutorado. Universidade de São Paulo. Disponível em http://www.teses.usp.br/teses/disponiveis/2/2134/tde-01092007-150125/en.php. Acesso em 1 de julho de 2018.

PEDRON, Flávio Quinaud. Mutação constitucional e crise do positivismo jurídico. Belo Horizonte: Arraes, 2012.

PEDRON, Flávio Quinaud. Comentários sobre as interpretações de Alexy e Dworkin. Revista CEJ, v. 9, n. 30, p. 70-80, 2005. Disponível em: www.jf.jus.br/ojs2/index.php/revcej/article/viewArticle/680. Acesso em 2 de julho de 2018.

RAWLS, John. A theory of justice. Cambridge: Harvard University Press, 1971.

SANTOS, Milton. Por uma outra globalização - do pensamento único à consciência universal. Rio de Janeiro: BestBolso, 2011.

SAVIGNY, Friedrich Karl von. Metodologia Jurídica. Tradução de Hebe Marenco. Campinas: Edicamp, 2001. 
SILVA, Virgílio Afonso da. Interpretação constitucional e sincretismo metodológico. in: Virgílio Afonso da Silva (org.), Interpretação constitucional, São Paulo: Malheiros, 2005. p. 115-143. Disponível em: https://constituicao.direito.usp.br/wp-content/uploads/2005Interpretacao_e_sincretismo.pdf. Acesso em 12 de junho de 2018.

SILVA, Joana Maria Madeira de Aguiar. Para uma teoria hermenêutica da justiça. Repercussões jusliterárias no eixo problemático das fontes e da interpretação jurídicas. Tese (Doutorado em Ciências Jurídicas) - Escola de Direito. Universidade de Minho. Portugal. 2008.

STRECK, Lenio Luiz. Dicionário de hermenêutica: quarenta temas fundamentais da teoria do direito à luz da crítica hermenêutica do Direito. Belo Horizonte: Letramento; Casa do Direito, 2017.

Hermenêutica jurídica e(m) crise: uma exploração hermenêutica da construção do direito. Porto Alegre: Livraria do Advogado, 1999.

WARAT, Luis Alberto. Introdução geral ao direito: interpretação da lei: temas para uma reformulação. v. 1. Porto Alegre: Sergio Antonio Fabris, 1994.

Introdução geral ao direito: a epistemologia jurídica da modernindade.

v. 2. Porto Alegre: Sergio Antonio Fabris, 2002.

Data de Submissão: 01/03/2020

Data de Aceite: 29/03/2020 